\title{
MEMORIAS POSIBLES PARA EL MOVIMIENTO TRANS* EN ECUADOR
}

\section{Resumen}

En los últimos veinte años, Ecuador ha experimentado una serie de transformaciones en materia de derechos sociales que incluye a las personas trans*. En 1997, la homosexualidad dejó de ser un delito y a partir de ese momento quienes fueron consideradas personas delincuentes y enfermas pasaron a convertirse en ciudadanas y sujetos de derechos. El movimiento travesti, transgénero y transexual ha devenido en un sujeto político que ha resistido las más crueles represiones para alcanzar una vida más vivible (Butler 2017). Mediante una metodología cualitativa que incluye entrevistas a activistas, relatos de prensa, documentos bibliográficos y experiencias compartidas del activismo LGBTI+, proponemos un ejercicio de construcción de memoria trans*.

Palabras clave: Activismo, Estado, memoria, trans ${ }^{*}$, Ecuador.

\section{Abstract \\ Possible memories for the Ecuador trans* movement}

In the last twenty years, Ecuador has experimented a number of transformations in social rights that include trans* people. In 1997, homosexuality was no longer considered a crime. From then on, those who were once considered criminals and disturbed individuals became citizens and subjects of rights. Travestites, transgender and transsexual movements have evolved into political subjects that have resisted the cruelest repressions in order to achieve a more livable life (Butler 2017). Using a qualitative methodology grounded in interviews with activists, press articles, biographical documents and LGBTI+ activist shared experiences, we present an exercise of trans* memory construction.

Keywords: Activism, state, memory, trans*, Ecuador.

\footnotetext{
* Doctorando del Programa de Doctorado Interuniversitario en Estudios de Género: Culturas, Sociedades y Políticas de la Universidad de Girona, Departamento de Psicología, Instituto de Investigación sobre Calidad de Vida. Becario de la Secretaría Nacional de Educación, Ciencia Tecnología e Innovación de Ecuador Senescyt.

Dirección postal: C/ M. Aurèlia Capmany, 38, Campus Montilivi, 17003 Girona. España.

Correo eletrónico: sancho.ole78@gmail.com

** Investigador Juan de la Cierva, Departamento de Psicología de la Universidad Autónoma de Barcelona. También es investigador del Proyecto i+d VOSATEC, MINECO (2016-18), ref. FFI2015-65947-C2-1-P; y del Proyecto Europeo Cruisingthe 1970s CRUSEV' (2016-19), European Science Foundation, ref. CRP 5087-00242

Dirección postal: Dep. de Psicologia Social, Fac. de Psicologia, Edifici B, Campus de Bellaterra 08193 Bellaterra. España.

Correo electrónico: r.l.platero@gmail.com
} 


\section{Resumo}

\section{Memórias possíveis para o movimento trans* no Equador}

Nos últimos vinte anos, o Equador passou por uma série de transformações em matéria de direitos sociais que incluiu as pessoas trans*. Em 1997, a homossexualidade deixou de ser um crime e, a partir daquele momento, aqueles que eram considerados delinquentes e doentes tornaram-se cidadãos e sujeitos de direitos. O movimento travesti, transgénero e transexual tornou-se um sujeito político que resistiu às mais cruéis repressões para alcançar uma vida mais vivível (Butler 2017). Através de uma metodologia qualitativa que inclui entrevistas com ativistas, recolha de imprensa, documentos bibliográficos e experiências compartilhadas do ativismo LGBTI+, propomos um exercício de construção da memória trans*.

Palavras-chave: Ativismo, Estado, memória, Trans *, Equador.

\section{Introducción}

Durante los últimos veinte años en Ecuador se han producido transformaciones y movilizaciones desde diferentes ámbitos sociales, provocando la emergencia de sujetos políticos cuyas vidas fueron criminalizadas por su orientación sexual, expresión e identidad de género. Eran vidas que estaban despojadas de la noción de lo humano (Stryker 2017), condenadas a la clandestinidad y persecución; por ende, recuperar su historia constituye un desafío necesario.

Hablar de una memoria trans ${ }^{* 1}$ puede ser complejo en un país donde la homosexualidad fue considerada un delito hasta hace apenas veinte años; sin embargo, cabe preguntarse; ¿Por qué hablar de una memoria del movimiento trans* en Ecuador? ¿Cómo construir tal memoria? Para responder, proponemos un itinerario político de quienes experimentaron cruentas represiones para alcanzar una vida más habitable (Butler 2017), pasando de ser consideradas delincuentes, enfermas, y más tarde, ciudadanas.

Entendemos la memoria «como un proceso social de reconstrucción de un pasado significativo para un grupo, colectivo o sociedad» (Mendoza García 2017, 19). Recurrimos a testimonios que generan cierta «temporalidad trans*» (Valentine 2007), con relatos que implican «experiencias subjetivas situadas históricamente» (Pons Rabasa y Garosí 2016, 307), pero sin ser un relato oficial de las luchas trans*, sino un aporte colectivo de algunas de sus protagonistas.

Utilizando la despenalización de la homosexualidad en 1997, articulamos tres momentos posibles para una temporalidad trans*. El primero expone las vivencias de travestis que vivieron la represión cuando la homosexualidad era considerada delito; el segundo, explica la politización del activismo trans* hasta la

Utilizamos trans* con asterisco, siguiendo a Cabral (2009) y Tompkins (2014), para dar cuenta de la multitud de posibilidades a la hora de concebir el cuerpo, la identidad y las vivencias que van más allá de las normas sociales binarias impuestas. 
conformación de la Asamblea Nacional Constituyente y la elección de Rafael Correa como presidente. El tercer período analiza los activismos trans* a partir de la expedición de la Constitución hasta la actualidad.

El estudio de este contexto no sólo es una descripción histórica dentro de una narrativa global que se repite, sino que es un esfuerzo político por construir una historia con matices vernáculos y un valor político propio (Lister 2011). Proponemos finalmente algunas conclusiones que remarcan la necesidad de aportar «genealogías críticas de lo trans ${ }^{*}$ » desde otros espacios de resistencia (Pons Rabasa y Garosi 2016, 309).

\section{El delito de homosexualismo}

Desde 1972, estaba vigente una legislación que sancionaba el delito de homosexualismo (Caicedo y Porras 2010, 560), señalando en el art. 516 inciso primero del Código Penal: «En los casos de homosexualismo, que no constituyan violación, los dos correos serán reprimidos con reclusión mayor de cuatro a ocho años». Castigaba las relaciones entre varones, pero no se tipificaba sanción directa al homosexual, ni se hablaba de transexualidad o lesbianismo. ${ }^{2}$ En la práctica, la policía detenía arbitrariamente a personas trans ${ }^{*}$ y homosexuales afeminados cuya identidad de género no correspondía con su sexo asignado al nacer, cebándose con las personas trans* que se dedicaban a la prostitución callejera. De acuerdo a este testimonio:

Los escuadrones volantes nos metían en el camión y nos llevaban al Centro de Detención Provisional CDP de Guayaquil. Allí ocurrían los atropellos más horribles que te puedas imaginar. Obligaban a las chicas travestis a servir sexualmente a los presos y a los policías, nos violaban, nos pegaban y si intentábamos reclamar nos amenazaban con dejarnos presas más tiempo. Muchas chicas trans aparecían muertas en la Perimetral con cortes, mutilaciones y nadie podía reclamar nada. (Entrevista a Alondra, ${ }^{3}$ realizada en 2015)

En el contexto histórico ecuatoriano de las décadas de 1980 y 1990 no se establecía una diferenciación tácita entre homosexualidad, transexualidad y travestismo. Como en otros lugares, la transexualidad y el travestismo eran concebidas socialmente como prácticas extremas de homosexuales afeminados que decidían «vestirse de mujer» para saciar sus perversiones fetichistas. Estos criterios respondían a la tradición del saber psiquiátrico que mantenían a la homosexualidad y la transexualidad como patologías en el DSM III y IV, un ámbito que generó el concepto de transexualidad en las décadas de 1950 y 1960 y que ha ido transformándose en una categoría social, no sólo en una categoría psiquiátrica. En este artículo no pretendemos hacer una discusión genealógica de los usos de las categorías de homosexualidad, travestismo y transexualidad ya que esto podría explicarse en otra investigación.

3 Los nombres reales de las entrevistadas han sido modificados para proteger su identidad personal. 
El cuerpo travesti callejero visible en Quito y Guayaquil interpelaba el ordenamiento moral de estas urbes y escandalizaba a la burguesía. Alberto Cabral (Purita Pelayo), ${ }^{4}$ militante travesti y líder de Coccinelle, narra la dura represión:

Cuando algún patrullero de la policía nacional o vehículo con agentes del SIC rodaban durante el día por la ciudad y tropezaban con algún homosexual visible, travesti o transexual, siempre había la intención de detenerlos por el simple hecho, según ellos, de ser «maricones». Muchas veces fueron detenidos sin mostrar formalmente documento alguno que justifique la detención. Eran días de zozobra, se reactualizaba con indignación la época de la Gestapo de los años treinta y cuarenta de la Alemania nazi, cuando realizaban redadas a judíos y homosexuales. (Cabral 2017,45)

En este escenario represivo, se generó «una inicial articulación de demandas por parte de actores dispersos, en donde se comienzan a formular marcos de injusticia que activan la acción colectiva» (Argüello 2013, 141). Las travestis realizaban acciones solidarias para sacar de la cárcel a sus compañeras, contexto en el que surge un motor para futuras movilizaciones amparado en la frase «hay que hacer algo» (Cabral 2017).

Desde las décadas de 1980 y 1990, se conformaron varias organizaciones, como la agrupación Sociedad Gay (SOGA) en Quito y Guayaquil, la Fundación Ecuatoriana de Ayuda, Educación y Prevención del Sida en Quito, dedicadas a promover la salud sexual. A pesar de su acción, las travestis percibían que este trabajo les era ajeno (Cabral 2017, 167-168).

\section{La lucha travesti callejera}

Durante las décadas de 1980 y 1990, el travestismo se asoció a una perversión fetichista de homosexuales que se vestían de mujer para saciar sus deseos sexuales con hombres y la prensa sensacionalista representaba a las travestis como mecos, desviados sexuales, enfermos y sodomitas. ${ }^{5}$ A pesar de esta hostilidad, en Ecuador y muchos países de América Latina, se generó una forma de resistencia a partir de la apropiación de la categoría travesti, a diferencia de Estados Unidos y Europa,

4 Se utiliza el nombre masculino de esta activista respetando su decisión de mantenerlo y visibilizar su militancia histórica tanto como Alberto como Purita. Sus memorias personales están recogidas en el libro Los fantasmas se cabrearon. Crónicas de la despenalización de la homosexualidad en el Ecuador donde narra su tránsito en el activismo.

$5 \quad$ Ver el Informe hemerográfico correlacionado con los cambios legales relativos a la orientación sexual y la identidad de género en Ecuador, del Banco Interamericano de Desarrollo, disponible en <https:// siluetax.files.wordpress.com/2012/06/bid-informe-hemerogrc3a1fico-correlacionado-con-los-cambios-legales-relativos-a-la-orientacic3b3n-sexual-y-la-identidad-de-genero-en-ecuador-1990-a-2013-por-diane-rodriguez.pdf $>$. 
donde fue rechazada por su tradición patológica. Lo travesti en Latinoamérica posee trayectorias propias, como señala Lohana Berkins:

El travestismo irrumpió en el espacio público de la mano de discursos biomédicos, policiales, sociológicos, jurídicos, políticos y periodísticos que funcionaron como disparadores en algunas ocasiones para discutir y en otras oportunidades para reforzar las dinámicas desiguales relacionadas con la identidad de género, la sexualidad, la raza, la clase social, la etnia, la religión, la edad, la ideología en diferentes contextos. De modo que cuando pensamos en el travestismo latinoamericano pensamos en un fenómeno complejo y dinámico y nos referimos a sujetas atravesadas por relaciones de privilegio y opresión propias de cada sociedad y de cada momento histórico particular. (Berkins 2010, 4)

La categoría travesti «refleja la particularidad de un tipo de identidad de género que debe ser pensada siguiendo el contexto social, cultural e histórico en el que es creada» (Vartabedian 2014, 307). Respecto a las formas locales de entender lo travesti, se refiere a personas que hacen una «reflexión diversa sobre su subjetividad, corporalidad y forma de hacer política» (Platero 2017,409). El travestismo ha «hecho referencia preferentemente a personas que llevan ropa atípica de su género pero que no emprenden ningún tipo de proceso de modificación corporal. [...] Suele hacer alusión a hombres más que a mujeres» (Stryker 2017, 71).

Retomando el itinerario trans ${ }^{*}$, las primeras movilizaciones fueron protagonizadas por trabajadoras sexuales travestis en Quito y Guayaquil. La calle era un entorno de violencia policial, pero también un espacio de resistencia. Algunas travestis denunciaron los atropellos que sufrían ante organizaciones de derechos humanos, pero no trascendían «más allá de las formalidades, no había seguimiento por parte de algún organismo interesado en tratar y defender los derechos de la comunidad GLBTI» (Cabral 2017, 165).

Las travestis crearon alianzas en la cárcel y en las calles para organizarse contra la violencia (Cabral 2017, 165) y enmarcaron su lucha en términos de derechos humanos. Parte de la resistencia travesti tomó formas lúdicas, como los reinados de belleza clandestinos en Quito, Guayaquil y Cuenca, y, como veremos, fue precisamente en un reinado travesti donde se generó una revuelta que hizo detonar una lucha más articulada.

\section{Delincuentes, enfermas y ahora ciudadanas}

La primera asociación de travestis y transexuales fue Coccinelle, que surgió en 1997 en Quito (Cabral 2017, 175), un año marcado por el descontento social, el deterioro de la institucionalidad del Estado y la corrupción. También se produjo 
un acontecimiento que marcó un nuevo rumbo para el activismo LGBTI,$+{ }^{6}$ el 18 de junio de 1997, mientras se celebraba un reinado travesti en el Bar Abanicos de la ciudad de Cuenca, la policía irrumpió violentamente y capturó aproximadamente a cien personas. La ganadora del reinado experimentó las más crueles vejaciones:

En uno de los dos únicos bares que existía en aquel entonces en Cuenca, se realizó una elección para reina de la comunidad; yo concursé y gané. Mientras me premiaban con el reinado, el Intendente de Policía llegó para hacer una «batida»; solo al bar [...]. El Intendente entró al bar y me pilló con la corona, el vestido, la banda y todo; entonces, me dijo a mí primero: ¡sal tú al carro! Al salir, me doy cuenta que me seguían atrás más de 60 chicos que estaban en el bar. Nos llevaron presos. En aquel entonces existía el CDP que eran unos cuartos nada más, uno de mujeres y otro de hombres. En ese cuarto estábamos más de 150 personas. Allí, los mismos delincuentes procedieron a violarme. Mientras eso sucedía, los policías se pusieron a vender preservativos a 5.000 sucres. El Intendente no me quería dar mi boleta de libertad y quería juzgarme él personalmente por como yo andaba vestido. [...] Un amigo llamado Patricio Santa Cruz que ya había salido, viendo el infierno donde estaba yo, se fue directamente a la oficina de los Derechos Humanos y ellos inmediatamente fueron a la Intendencia; allí no les quisieron dar información. Como mi hermana estaba ahí, hablaron con ella y fueron a verme. Cuando el abogado de los derechos humanos se acerca a mi hermana al CDP, no dan explicaciones de nada; regresan a la Intendencia y les obligan a darle a mi hermana la boleta de libertad (Patricio Cuéllar, citado en CNIG 2014, 33-34).

Esta agresión fue la «gota que derramó el vaso»,7 y su denuncia generó la movilización colectiva para exigir al Tribunal Constitucional la despenalización de la homosexualidad. Dicho Tribunal requería mil firmas con el respectivo número de cédula, un reto para las organizaciones de homosexuales ya que cumplir con este requisito implicaba dar la cara públicamente.

La alianza travesti fue nuevamente necesaria ya que «ellas ganaban más recolectando las firmas y reivindicando la lucha antipenalización que seguir viviendo rutinariamente estas marcas de discriminación» (Argüello 2013,132). Coccinelle cumplió un papel fundamental para convencer a la ciudadanía que diera su firma para despenalizar la homosexualidad y el 27 de noviembre de 1997 el Tribunal Constitucional declaraba inconstitucional el artículo 516 inciso primero del Código Penal.

Empleamos la sigla LGBTI+ para indicar una forma abierta de identificaciones políticas respecto al género y la sexualidad, que en el caso ecuatoriano ha experimentado una evolución de acuerdo a las agendas de los colectivos.

Entrevista a Brigith, realizada en 2016. 


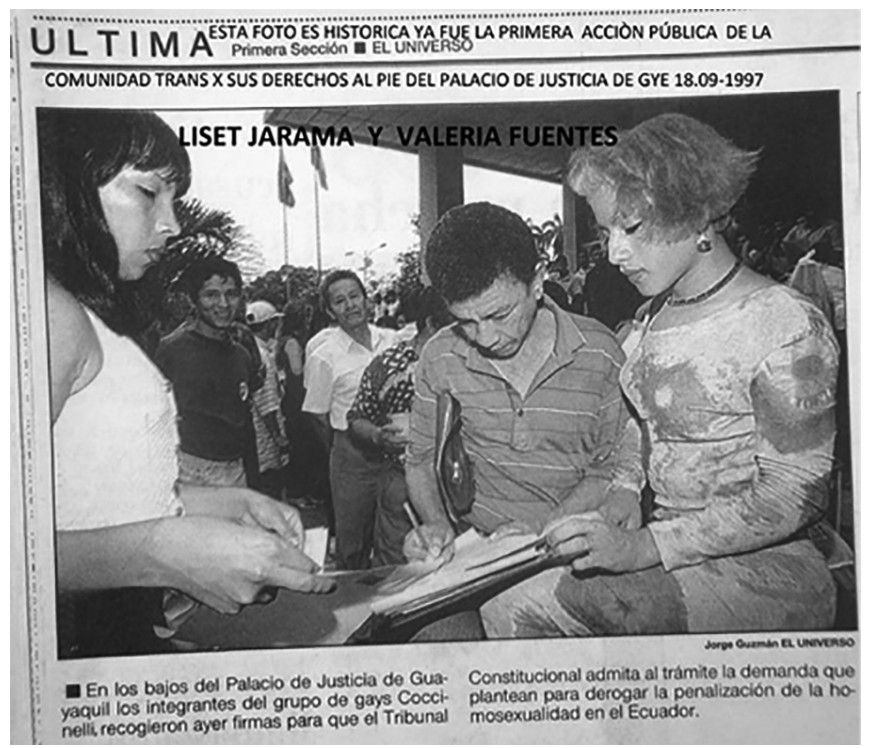

Figura 1. Diario El Universo, 18 de septiembre de 1997, cortesía de Gonzalo Abarca.

La despenalización de la homosexualidad se dio bajo un argumento desagradable del Tribunal Constitucional: «el homosexualismo era una enfermedad, que la condición de enfermedad eximía de responsabilidad delictiva y que despenalizar esta enfermedad evitaría que se propagara en las cárceles» (Almeida y Vásquez 2010, 30-31). Esta argumentación colocó «a la homosexualidad en el espacio de la anormalidad, a pesar de sostener que no debería ser punible en el ámbito del Derecho Penal» (Salgado 2008, 31).

Conseguida la despenalización de la homosexualidad, se pronuncia la frase que forma parte de la memoria LGBTI+: «Pasamos de delincuentes, a sujetos de derechos, de maricones y tortilleras a ciudadanos». ${ }^{8}$ Cabe preguntarse, ¿cómo fue posible la construcción de nuevos sujetos políticos que antes habían sido criminalizados? El activismo trans* ya había generado pequeños procesos de politización en su lucha callejera como lo hemos visto, así «la necesidad de 'transformar esos delincuentes en ciudadanos' no debe ser entendida como una casualidad» (Argüello 2013, 128).

La movilización de disidentes sexuales incide entonces en la inclusión de la no discriminación por orientación sexual en el artículo 23 numeral 3 de la Constitución de la República (1998) y en 1999 se creó el Plan Nacional de Derechos Humanos, que incluía un Plan Operativo de Diversidad Sexual, cuya base legal

Esta frase fue atribuida al activista Patricio Bravomalo(+), sin embargo, se volvió un relato oral colectivo para el activismo LGBTI+. 
era la igualdad y no discriminación (Almeida y Vásquez 2010, 28). Estas iniciativas no necesariamente implicaron la transformación de las prácticas de odio a las personas trans* (Spade 2015).

Coccinelle pasó a ser la Fundación de Minorías Sexuales (FEMIS) en 1999; sin embargo, las disputas internas entre sus integrantes hicieron que se desintegrase (Cabral 2017). Entre 2000 y 2006 se conformaron colectivos trans* con diversas agendas, como el Proyecto Trvnsgén3ro en Quito (Almeida y Vásquez 2010, 12), la Fundación Jem Rodríguez en Guayaquil y la Asociación Alfil en Quito .En la Provincia de Santa Elena, surgió la Fundación de Transgéneros Peninsulares (FUTPEN); en la ciudad de Manta,se constituyó la Agrupación Luchando por la Vida (LUVID). También surgieron iniciativas en Machala, Portoviejo, Santo Domingo y Esmeraldas.

Estas organizaciones posicionaron en sus agendas el concepto trans* como una identidad estratégica más abarcadora, adoptando una política transnacional del género, el cuerpo y la sexualidad. La globalización de lo trans* se dio en el marco de una militancia norteamericana que cobró fuerza en la década de 1990 y posicionó «el concepto transgénero como un paraguas para indicar la pluralidad de experiencias que cuestionaban la coherencia, la estabilidad y la correspondencia entre género, cuerpo y deseo» (Pons Rabasa y Garosi 2016, 313).En Ecuador, el aterrizaje de lo trans* desde el Norte global se da a través de un activismo que formó a otras agrupaciones:

Me acuerdo cuando me gané la beca que fui la única de aquí de Manabí que fui a la Casa Trans en Quito. Cuando comenzaron a hablar de trans, decían las chicas de Guayaquil: ¡Ah! pero yo no estoy trastornada, decía la de Esmeraldas, pero, ¿qué es trans? Me van a trazar o qué, ¿qué será? Era un vocabulario que no entendíamos. Al otro día vino el transgénero, pero decíamos, ¿y ahora que nos van a enseñar? Ese era el vocabulario que se hablaba en ese entonces, ya en el 2004, 2005, 2006 cuando empezó el Proyecto Trvnsgén3ro. En la capacitación nos sacaron adelante a poner dos diferencias: una chica biológicamente mujer que era trans masculino y una chica trans que era biológicamente masculino. Y así fue donde comenzaron a identificarnos realmente que éramos y que no éramos (Entrevista a Sheila, realizada en 2016).

Este testimonio evidencia la acogida de lo trans* a través de la formación política de agrupaciones que desconocían tal concepto. Cabe resaltar que en la Costa ecuatoriana han existido desde la época prehispánica personas que no se han identificado con el género asignado al nacer, como «los enchaquirados» (Benavides2006, 2017). Las maneras de asumir lo trans* en un mismo espacio geográfico son variables, así en entornos urbanos de Quito y Guayaquil permitió politizar una «identidad estratégica para promover el reconocimiento de derechos para las personas trans» (Pons Rabasa y Garosí 2016, 320).En contextos rurales, lo trans* adquiere otro sentido: 
Yo le digo a las chicas, hablando de la comunidad transgénero, la que cree que por vestirse de mujer, ponerse blusa, pintarse, ya son mujeres, entonces le digo, la importancia para mi radica en esto de enseñarnos que es ser una persona transgénero y que es un travestí. Empiezas a crear una cultura dentro de tú persona, empiezas a entender que quieres y qué quieres que la gente vea de ti, es lo que yo le digo a los chicos que me conocen: el ser mujer es un conjunto de muchas cosas de querer ser una mujer; es tratar de que esa identidad que hemos adoptado tenga lo más parecido a lo que una mujer biológica es. Jamás nos vamos a igualar cien por ciento por más que queramos a una mujer (Entrevista a Alba, realizada en 2016).

Las trayectorias de lo travesti a lo trans* encierran múltiples subjetividades que podrían denotar una higienización del género asumido. Durante el trabajo de campo en distintas ciudades, se evidenció que no todas las personas quieren ser identificadas como trans*; se precisa entonces analizar críticamente los desplazamientos de categorías que pueden implicar una violencia epistémica que anule el entramado vernáculo de las construcciones socioculturales del género y la sexualidad. En este sentido, existe un esfuerzo por respetar formas «criollas» de asumir lo trans* como los términos «macha» $\mathrm{y}$ «hembro» asumidos políticamente por el Proyecto Trvansg3nero.

\section{Activismos trans* en la era de la Revolución Ciudadana9}

En 2007, el presidente Rafael Correa Delgado convocó un referéndum sobre la adopción de una Asamblea Constituyente con plenos poderes y elaborar una nueva Constitución (Argüello 2013, 136), consulta que fue aprobada por el 82\% de la ciudadanía. El liderazgo de Correa simboliza la confluencia del populismo de izquierdas, un neoliberalismo adaptativo y un conservadurismo social que se suele identificar con la aparición de nuevos regímenes de seguridad en el Sur global (Amar 2013). Su gobierno también generó oportunidades para activistas LGBTI+ que postularon sus candidaturas en la Asamblea Constituyente. Sin embargo, la agenda LGBTI+ no fue unificada: el activismo lésbico se alió a la agenda del movimiento de mujeres y los gais se centraron en la unión de hecho y el matrimonio civil igualitario.

La militancia trans* encabezada por asociaciones como Alfil, Red Trans de El Oro, FUTPEN y Silueta X asumieron la identidad de género como derecho prioritario para la nueva Constitución. Por su parte, el Proyecto Trvnsgén3ro decidió articularse en la «Alianza Transfeminista de Presencias Incómodas» y el «Movimiento Ecuatoriano de Diversidades Sexuales» (Entrevista a Elizabeth Vásquez,

Revolución Ciudadana es el eslogan que utilizó el partido Alianza País, y fue la base del discurso político de Rafael Correa entre 2007 y 2015. 
2015) en «una agenda con colectivos feministas, el movimiento de migrantes, indígenas y rockeros con quienes trabajamos los temas de las estéticas y el aborto» (Vásquez citada en CNIG 2014, 56).

En la Asamblea Nacional Constituyente se produjeron intensos debates sobre la identidad de género, la unión de hecho entre parejas del mismo sexo y el aborto. A pesar de las tensiones conservadoras, se aprobó la Constitución de la República mediante referéndum el 28 de septiembre de 2008, con un $64 \%$ de votos a favor. En este escenario se conformaron agrupaciones trans* como Silueta X, liderada por Diane Rodríguez. Desde el 2008, se visibilizaron activismos trans* masculinos impulsados desde el Proyecto Trvnsgén3ro, que cofundó la Confederación Ecuatoriana de Comunidades Trans e Intersex, cohesionando agrupaciones trans * en distintas provincias.

Los activismos trans* se centraron en el principio de igualdad y no discriminación consagrado en la Constitución, concretamente en el derecho a la identidad de género (art. 11 numeral 2) y el derecho a la libertad de estética (art. 21), así como enla aprobación de una legislación penal que sancione la discriminación y los delitos de odio por razones de orientación sexual e identidad de género. ${ }^{10}$ Este marco jurídico podría ser identificado como beneficioso para las personas trans*; no obstante, su aplicación genera discusiones respecto al alcance de una justicia sexual real especialmente en ámbitos como la salud, la educación, el trabajo y la familia (Spade 2015). ${ }^{11}$

A pesar de los límites del derecho, se idearon varias estrategias para la protección jurídica de las personas trans*. Por ejemplo, en 2007, el Proyecto Trvnsgén3ro demandó al Registro Civil por negarse a cedular a la ciudadana Luis Enrique Salazar (Gabriela Salazar) de acuerdo a su identidad de género. Obtuvo una demanda favorable y sentó un precedente que posibilitó: «a) mostrar las prácticas discriminatorias del Registro Civil, b) permitir la cedulación de las personas trans con la estética que poseen, c) permitir la cedulación por cambio de sexo» (Argüello 2014,136).

Otro caso paradigmático fue el de Estrella Estévez, quién en 2009 presentó una solicitud al Registro Civil para que se reconociera su identidad de género femenina en la cédula de ciudadanía. La Dirección de Registro Civil, Identificación

10 El Código Orgánico Integral Penal del Ecuador (2014) tipifica, en el art. 176, penas de privación de la libertad de uno a tres años a quién cometa el delito de discriminación por motivos de orientación sexual e identidad de género. El art. 177 prescribe pena privativa de la libertad de 22 a 27 años a quién cometiera un delito de odio que produjera la muerte de una persona en razón de su orientación sexual e identidad de género. La actual legislación penal superó la reforma que se realizó al Código Penal en 2009 añadiendo la identidad de género en la prescripción de los delitos de odio.

11 Sobre situación de las personas trans*, véase: Una Aproximación a la Situación de los Derechos Humanos de las Personas Trans en Ecuador, publicado en 2017 por el Consejo Nacional para la Igualdad de Género y disponible en <https://www.igualdadgenero.gob.ec/genero-y-diversidades/>. 
y Cedulación negó su petición y Estévez presentó un recurso de apelación ante la Corte Provincial de Justicia de Pichincha, que emitió un fallo favorable basado en el reconocimiento de la identidad como derecho humano consagrado en la Constitución. Fue la primera persona trans ${ }^{*}$ que logró el reconocimiento legal coherente de sus nombres y su sexo legal femenino en su cédula, ${ }^{12}$ pero no sentó una base jurisprudencial vinculante. La Ley del Registro Civil vigente permitía el cambio de nombre legal, pero mantenía en la cédula de ciudadanía la categoría sexo (femenino o masculino), creando una incongruencia legal de identificación.

Entonces el Proyecto Trvnsgén3ro presentó la «Propuesta de Reforma a la Ley de Registro Civil, Identificación y Cedulación en materia de Identidad de Género» (R/LRCIC-IG), conocida como «Mi género en Mi Cédula» (Vásquez 2016, 197). Esta propuesta concebía que «la consecución de ciudadanía se daría si el Estado hiciera efectivo el reconocimiento de la identidad de género por sobre el sexo: dejar de registrar el sexo de las personas para empezar a reconocer su género» (Argüello 2014, 118). Esta campaña «formó parte de un proceso social y político de más de diez años de trabajo sostenido tanto con la población trans (in situ) como con la producción de estructuras de sentido que han posicionado la temática en la esfera pública» (Argüello 2014, 125).

Sin detenernos a analizar el significado jurídico de esta propuesta, posibilitaría una inclusión plena de las personas trans* asumiendo el género como categoría universal. Independientemente del sexo o la orientación sexual, prevalecería la categoría identificativa del género, que corresponde a la presentación corporal de su masculinidad o feminidad. Lo que se ponía bajo reserva, era el sexo de un individuo entendido como el dato concerniente a su genitalidad; así, al constar en la cédula la categoría género y no sexo, se lo preservaría como dato íntimo.

En términos prácticos, las personas trans ${ }^{*}$ no tendrían la necesidad constante de «dar cuenta de sí mismas» (Butler 2009) para que se compruebe su inteligibilidad corporal, sexual y genérica. La propuesta fue aprobada en la Asamblea Nacional en 2013; sin embargo, el gobierno desplegó una campaña contra la llamada «ideología de género». En el Enlace Ciudadano 354 del 28 de diciembre de 2013, el presidente Correa se refirió a la ideología de género como algo que no «resiste el menor análisis» $\mathrm{y}$ «una barbaridad que atenta contra todo», «leyes naturales... contra todo». Añadió: «Porque somos, gracias a Dios, hombres y mujeres diferentes, complementarios; y no es que se trate de imponer estereotipos, pero iqué bueno que una mujer guarde sus rasgos femeninos! ¡Qué bueno que un hombre guarde sus rasgos masculinos!»

Correa aludía a una verdad natural sobre el sexo, descartando la posibilidad de construcción social de la feminidad o la masculinidad producida por el género. Paradójicamente, este mismo presidente se reunía en diciembre de 2013 con coleccontenía el dato relativo al Sexo de la persona y no el Género. 
tivos como Silueta $X$, para establecer un acuerdo de políticas públicas para la población LGBTI+ (Compromiso Presidencial 21525), delegando al Ministerio Coordinador de Desarrollo Social la elaboración de una Política Pública Nacional e Intersectorial donde participarían otros ministerios.

A partir de esta reunión y el nombramiento de Diane Rodríguez como vocera ante el gobiernose produjo una polarización y atomización de los activismos LGBTI+, frente a la arrogación de representatividady los personalismos. Pese a las tensiones, el movimiento trans* coincidió en que la garantía integral de sus derechos solo sería posible si se reconocía plenamente sus identidades. Como ya se ha mencionado, los colectivos trans* emprendieron desde el año 2012 una campaña para la aprobación del género como categoría universal en la Ley de Gestión de la Identidad y Datos Civiles.

Mientras un sector del movimiento trans* estaba implicado en hacer efectivo el reconocimiento del género, se creó en 2015 la Federación Ecuatoriana de Organizaciones LGBTI con Diane Rodríguez como presidenta, articulando agrupaciones que se aliaron al partido de gobierno (Ministerio de Justicia, Derechos Humanos y Cultos 2015). La creación de esta instancia no fue casual, permitiendo la cooptación de un sector del movimiento LGBTI+ alineado a su postura política populista.

En este escenario, la Asamblea Nacional aprobó en 2015 la Ley Orgánica de Gestión de la Identidad y Datos Civiles, permitiendo el veto parcial de la Presidencia de la República, y su objeción a la constancia del género como dato civil universal en lugar del sexo en la cédula de ciudadanía. El artículo 94 de esta ley contempla el sexo como uno de los datos obligatorios de la cédula de ciudadanía y permite el cambio de sexo por género bajo las siguientes condiciones:

Voluntariamente, al cumplir la mayoría de edad y por una sola vez, la persona por autodeterminación podrá sustituir el campo sexo por el de género que puede ser: masculino o femenino. El acto se realizará en presencia de dos testigos que acrediten una autodeterminación contraria al sexo del solicitante y por al menos dos años, de acuerdo con los requisitos que para el efecto se determinen en esta Ley y su reglamento. Este cambio no afectará los datos del registro personal único de la persona relativos al sexo. De darse esta situación, el peticionario podrá solicitar el cambio en los nombres a causa de la sustitución del campo sexo por el de género (Ley Orgánica de Gestión de la Identidad y Datos Civiles) ${ }^{13}$.

Esta decisión trastocó el planteamiento original del género como categoría universal, ya que el sexo como categoría biológica en lugar del género como un elemento social de identidad continuaría siendo la categoría predeterminada en la

13 Disponible en <https://www.registrocivil.gob.ec/ley-organica-de-gestion-de-la-identidad-y-datos-civiles>. 
cédula de ciudadanía (Garriga-López 2016, 113). La plataforma Pacto Trans ${ }^{14}$ tildó la aprobación de esta ley como una «conquista agridulce y contradictoria», en tanto

crea una lamentable jerarquía [...] ya que por un lado tenemos la cédula correspondiente al grueso de la población con las opciones de «sexo»: «hombre» o «mujer» y, por otro lado, tenemos una cédula «minoritaria», que se vuelve exclusiva para nosotras las personas trans, y por ello nos estigmatiza, con las opciones de «género»: «femenino» $\mathrm{o}$ «masculino»(Pacto Trans 2017).

Se cuestionó también la tutela innecesaria de probar el género de una persona con dos testigos, en tanto constituía una «tecnología del género» (De Lauretis 2010).

Las contradicciones de un gobierno que se define progresista en lo económico pero conservador en asuntos relacionados con el aborto, el matrimonio igualitario y la «ideología de género» nos lleva a pensar en cómo el movimiento trans* produce un transwashing institucional, un lavado de cara a través de leyes que terminan siendo excluyentes. Las paradojas de las luchas trans* en la era de la Revolución Ciudadana se evidencian en las demandas continuas a un Estado que disciplina la autodeterminación individual de quienes deciden vivir fuera de las normas dominantes del género binario y cuyas leyes sobre delitos de odio no ha resuelto los asesinatos a personas trans*.. ${ }^{15}$

El movimiento trans* sigue reivindicando el derecho a una asistencia de salud libre de discriminación y respetuosa de sus corporalidades distintas, denunciando la insuficiente respuesta estatal. El Ministerio de Salud Pública elaboró en 2016 un Manual de Atención en salud LGBTI, con recomendaciones sobre la atención sanitaria trans* y que fue criticado por no contemplar pautas sobre la autodeterminación corporal. Frente a los límites de las políticas sanitarias, los activismos trans* idearon estrategias que van más allá de la interlocución con las instituciones, desarrollando pequeñas iniciativas de capacitación al personal de proximidad.

Para el movimiento trans*, el período entre 2007 y 2017 ha significado un desafío permanente. Las dinámicas asociativas tienen diversos matices que no siempre responden a la lógica institucional de las ONG; el cruce de «raza», clase, género y sexualidad se evidencia en las formas en que los activismos trans* se movilizan en cada localidad, desde el activismo urbano hasta las formas organizativas de trabajo comunitario en sectores rurales de la Costa y el Oriente del país.

En estos últimos años, el movimiento trans* ha enfrentado tensiones con sectores feministas esencialistas que ven con desconfianza sus agendas; sin embargo, la violencia de género articuló a feministas y personas trans* principalmente en

Ver $<$ http://pactotransecuador.blogspot.com.es $>$.

Ver el Informe Runa Sipiy. Asesinatos a personas TILGB 2015, disponible en <https://siluetax.org/ estudios $>$.). 
Quito, donde se ha venido realizando la Marcha de las Putas. El posicionamiento transfeminista del Proyecto Trvnsgén3ro establecía simetrías subyacentes de las mujeres trans ${ }^{*}$ con otros sujetos excluidos, como trabajadoras del sexo, punks o vendedores callejeros (Almeida y Vázquez 2010, 9), cohesionando los grupos trans* que no siempre contemplaron en sus agendas una perspectiva feminista.

\section{Conclusiones}

Hicimos un breve repaso de las luchas trans* en Ecuador durante los últimos treinta años y planteamos la necesidad de «recuperar la historia trans* como un acto político» (Platero 2015, 169), una memoria difícil de rastrear sin hacer un relato situado con matices propios. Es importante explicar con cautela cómo ha evolucionado el activismo trans* en Latinoamérica, donde las luchas por la supervivencia se tornan más complejas en un territorio de extrema desigualdad social. La crítica a las formas convencionales de activismo trans* enmarcadas en la retórica de exigencia de derechos al Estado puede resultar reduccionista sino se examinan los detalles de estas luchas. Paradójicamente a lo que ocurre en Estados Unidos o Europa, donde las identidades trans* han sido patologizadas, en Argentina, Colombia y Ecuador se ha reformulado «la cuestión de la ciudanía trans desde el paradigma de derechos humanos y la despatologización» (Pons Rabasa y Garosí 2016, 321).

Recuperar la memoria trans* supone analizar las cuestiones ético-políticas de la producción del conocimiento, para no incurrir en una repetición de un marco epistémico del Norte global para explicar historias que han tenido un tránsito distinto. Más allá de describir situaciones que podrían calificarse de anecdóticas, mostramos las subjetividades de cuerpos en resistencia que lideran cambios sociales importantes al tiempo que están marcados por las intersecciones de sus vivencias como personas que rompen las normas de género y la sexualidad pero que también son racializadas y precarizadas económicamente, entre otros marcadores sociales. Es una memoria que no se desprende de los afectos en aras de una racionalización continua de cada acto de las personas trans* para lograr una mejor vida. Estos testimonios replantean la idea, quizás utópica, de que otro mundo es posible y que «cada bocanada de aire que una persona transexual toma es un acto revolucionario» (Stryker 2016).

Las luchas trans* en un territorio compuesto por población indígena, afrodescendiente y mestiza nos interroga sobre la diferencia de cada itinerario de resistencia en un sistema de múltiples opresiones. La memoria no debe obviar aquellas vidas que no se consideran importantes, por ello son necesarios trabajos histórico-antropológicos de mayor profundidad que recuperen la riqueza ancestral de las personas no binarias en la Costa, Sierra y Oriente del país. 


\section{Agradecimientos}

A todas las personas trans* de Quito, Guayaquil, Portoviejo y Manta que aportaron sus valiosos relatos para construir esta memoria posible.

\section{Referencias bibliográficas}

Almeida, Ana, y Elizabeth Vásquez. 2010. Cuerpos distintos: Ocho años de activismo transfeminista en Ecuador. Quito: Comisión de Transición hacia el Consejo Nacional de Mujeres y la Igualdad de Género.

Amar, Paul. 2013. The Security Archipelago: Human-Security States, Sexuality Politics, and the End of Neoliberalism. Durham, NC: Duke University Press.

Argüello, Sofía. 2013. Un fantasma ha salido del closet. Los procesos de politización de las identidades sexuales en Ecuador y México, 1968-2010. México: El Colegio de México.

Argüello, Sofía. 2014. «¿Tiene sexo el Estado? Imbricaciones entre las luchas políticas transgénero y el Estado en Ecuador, 2002-2013». En Formas reales de dominación del Estado: perspectivas interdisciplinarias del poder y la política, coordinado por Alejandro Agudo Sanchíz y Marco Estrada Saavedra, 111-149. México DF: El Colegio de México, Centro de Estudios Sociológicos,

Benavides, O. Hugo. 2006. «La representación del pasado sexual de Guayaquil: historizando los enchaquirados». Iconos. Revista de Ciencias Sociales 24, 145-160.

Benavides, O. Hugo. 2017. «Transgéneros» en la costa ecuatoriana: una historia del presente evanescente. En Trans*. Diversidad de identidades y roles de género, coordinado por Andrés Gutiérrez Usillos, 119-123. Madrid: Ministerio de Educación, Cultura y Deporte, Museo de América.

Berkins, Lohana. 2010. «Travestis: Una identidad política». En Putos Peronistas. Material de Formación. Buenos Aires.

Butler, Judith. 2009. Dar cuenta de sí mismo. Violencia, ética y responsabilidad. Buenos Aires: Amorrortu.

Butler, Judith. 2017. Marcos de guerra: Las vidas lloradas. Barcelona: Paidós Ibérica.

Cabral, Mauro. 2009. Interdicciones. Escrituras de la intersexualidad en castellano. Córdoba: Anarrés Editorial.

Cabral, Alberto. 2017. Los fantasmas se cabrearon. Crónicas de la despenalización de la homosexualidad en el Ecuador. Quito: Fundación Regional de Asesoría en Derechos Humanos INREDH,

Caicedo Tapia, Danilo, y Angélica Porras Velasco. 2010. «Igualdad y diversidad sexual. La hegemonía de la heterosexualidad en el derecho ecuatoriano». En Igualdad y no discriminación. El reto de la diversidad, editado por Danilo Caicedo Tapia y Angélica Porras Velasco, 547-573. Quito: Ministerio de Justicia, Derechos Humanos y Cultos del Ecuador.

CNIG - Consejo Nacional para la Igualdad de Género. 2014. Balance y perspectivas de los derechos humanos de las personas LGBTI en el Ecuador a partir de la despenalización de la homosexualidad en el Ecuador. Quito: CNIG. Disponible en http://biblioteca.igualdadgenero.gob.ec/cgi-bin/koha/opac-detail.pl?biblionumber $=7255$

De Lauretis, Teresa. 2010. Diferencias. Etapas de un camino a través del feminismo. Madrid, Horas y horas, Cuadernos inacabados n. 35. 
Garriga-López, y Claudia Sofía. 2016. «Transfeminist Crossroads. Reimagining the Educadorian State». Transgender Studies Quarterly 3(1-2):104-119. DOI: https://doi.org/10.12 15/23289252-3334271

Lister, Ruth. 2011. «From the Intimate to the Global: Reflections on Gendered Citizenship.» En The Limits of Gendered Citizenship, edited by Elżbieta Oleksy, Jeff Hearn y Dorota Golańska, 27-41. Nueva York: Routledge.

Mendoza García, Jorge. 2017. «Lenguaje y memoria colectiva, silencio y olvido social». En Memoria colectiva de América Latina, coordinado por Manuel González Navarro y Jorge Mendoza García, 17-42. Madrid: Biblioteca Nueva.

Ministerio de Justicia Derechos Humanos y Cultos. 2015. «Tras Diálogo Nacional se conforma la Federación Ecuatoriana de Organizaciones LGBT». Disponible enhttps:// www.justicia.gob.ec/tras-dialogo-nacional-se-conforma-la-federacion-ecuatoriana-de-organizaciones-lgbt [consultado el 15 de noviembre de 2018].

Pacto Trans Ecuador. 2017. Blog Pacto Trans Ecuador. Disponible enhttp://pactotransecuador.blogspot.com.es/ [consultado el 10 de noviembre de 2018].

Platero, R. Lucas. 2015. «Recuperar la historia trans como acto político». En Memorias, identidades y experiencias trans. (In)visibilidades entre Argentina y España, editado por Jorge Luis Peralta y Rafael Mérida Jiménez, 169-192. Buenos Aires: Biblos.

Platero, R. Lucas. 2017. «Trans* (con asterisco)». En Barbarismos queer y otras esdrújulas, editado por R. Lucas Platero, María Rosón y Esther Ortega, 409-415. Barcelona: Bellaterra.

Pons Rabasa, Alba, y Eleonora Garosi. 2016. «Trans». En Conceptos clave en los estudios de género Volumen 1, coordinado por Hortensia Moreno y Eva Alcántara, 307-325. México: Universidad Nacional Autónoma de México-Centro de Investigaciones y Estudios de Género.

Salgado, Judith. 2008. La Reapropiación del Cuerpo: Derechos Sexuales en el Ecuador. Quito: Abya-Yala, UASB, Colección Magíster.

Spade, Dean. 2015. Una vida normal. La violencia administrativa, la politica trans crítica y los límites del derecho. Barcelona: Bellaterra.

Stryker, Susan. 2016. «Coged aire: Las políticas de vida transactuales». Ciclo de Conferencias Perspectivas Trans Críticas, Cultura Trans, Barcelona, 31 de mayo a 17 de junio.

Stryker, Susan. 2017. Historia de lo Trans. Las raíces de la revolución de hoy. Madrid: Continta Me Tienes.

Tompkins, Ivery. 2014. «Asterisk». Transgender Studies Quarterly 1(1-2): 26-27. DOI: https:// doi.org/10.1215/23289252-2399497

Valentine, David. 2007. Imagining Transgender: An Ethnography of a Category. Durham: Duke University Press. DOI: https://doi.org/10.1215/9780822390213

Vartabedian, Julieta. 2014. «El alcance político de las travestilidades: acerca del potencial transgresor de las travestis». Annual review of critical psychology 11: 299-317.

Vásquez, Elizabeth. 2016. «Mi género en mi cédula: Un concepto nuevo por una puerta vieja». En Queering Narratives of Modernity, editado por Maria Amelia Viteri y Manuela Picq, 197-214. Bern: Peter Lang.

Fernando I. Sancho Ordoñez. Doctorando del Programa de Doctorado Interuniversitario en Estudios de Género: Culturas, Sociedades y Políticas, de la Universidad de Girona, Departamento de Psicología-Instituto de Investigación sobre Calidad de Vida. Becario de la Secretaría Nacional de Educación, Ciencia Tecnología e Innovación de Ecuador Senescyt.

Correo eletrónico: sancho.ole78@gmail.com 
R. Lucas Platero. Doctor en Sociología y Ciencias Políticas por la Universidad Nacional de Educación a Distancia (UNED); Investigador Postdoctoral Juan de la Cierva, Dpto. Psicología Social, Universidad Autónoma de Barcelona, así como de los proyectos: VOSATEC (Ref. FFI2015-65947-C2-1-PDpto). Ciencia, Tecnología y Sociedad, Instituto de Filosofía del CSIC y del proyecto europeo CRUSEV (HERA.15.099, Horizon 2020), (Ref. 5087-00242 ${ }^{\mathrm{a}}$ ). Últimos libros son: Trans*exualidades. Acompañamientos, factores de salud y recursos educativos (2014); Por un chato de vino (2015) y Barbarismos queer y otras esdrújulas (2017).

Correo electrónico: r.l.platero@gmail.com

Artículo recibido el 30 de abril y aceptado el 22 de agosto de 2018. 
